\title{
Unmanned Radiation Monitoring System
}

\author{
Jakub Lüley \\ Institute of Nuclear and Physical \\ Engineering \\ Slovak University of Technology in \\ Bratislava \\ Bratislava, Slovakia \\ jakub.luley@stuba.sk \\ Filip Osuský \\ Institute of Nuclear and Physical \\ Engineering \\ Slovak University of Technology in \\ Bratislava \\ Bratislava, Slovakia \\ filip.osusky@stuba.sk
}

\author{
Branislav Vrban \\ B\&J NUCLEAR ltd. Miloslavov, \\ Slovakia \\ branislav.vrban@bjnuclear.eu
}

\author{
Štefan Čerba \\ B\&J NUCLEAR ltd. \\ Miloslavov, Slovakia \\ stefan.cerba@bjnuclear.eu
}

The absence of online radiation monitoring systems has been observed in the case of Fukushima nuclear accident. As the tsunami destroyed 23 of the 24 status monitoring points, almost no relevant radiation dose measurements data were available. A rapid deployment of a mobile radiological unit that can quickly determine the activity and direction of the radioactive cloud spread on the ground or in the air can prevent unnecessary deaths and related financial losses. Although the design of the current generation of NPPs incorporates features that minimize the risk of large radioactive releases outside the reactor, it is still important to focus on the development of systems that can mitigate the consequences of such events. In situations when the level of radiation does not permit the personal to perform the required measurements, online unmanned radiation monitoring systems may come to the play. For such a purpose the RMS-00x radiation monitoring system could be used, which is a modular system covering the functionality of dose rate measurement, air sampling and radiation map creation without requiring the human personnel to be present at the measurement site. The main purpose of the RMS-00x radiation monitoring system is the rapid deployment of unmanned monitoring devices to reduce the radiation burden on workers and on public. The system can be applied in the vicinity of a nuclear power plant (NPP) or at any location, where source of ionizing radiation could be present. Before this system is used in real conditions, its components must be thoroughly calibrated, based on certified measurement equipment and state-of-art simulation tools. This paper deals with the description of the RMS-00X sensor modules and demonstrates their functionality in combination with UAV. In addition, demonstration of the use of the developed technology was carried out as part of the regular emergency planning and preparedness of EBO NPP on 26th October 2017.

Keywords-RMS, UAV, radiation monitoring, accident, demonstration

\section{INTRODUCTION}

The absence of online radiation monitoring systems has been observed in the case of Fukushima nuclear accident. As the tsunami destroyed 23 of the 24 status monitoring points, almost no relevant radiation dose measurements data were available. The serious situation resulting from the accident led to the decision to evacuate the populations. This decision had been made on the basis of the parameters computed from the simulation models. The associated stress resulted from the invisible threat and the evacuation process caused significant socio-economic consequences and a death toll. The real radiological measurement proofed that the effective radiation dose had not exceed the daily limits in some areas and showed needless of evacuations. More information with the monitoring results can be find in [1]. A rapid deployment of a mobile radiological unit that can quickly determine the activity and direction of the radioactive cloud spread on the ground or in the air can prevent unnecessary deaths and related financial losses. Unmanned Aerial Systems (UASs) used for the monitoring of the radiation situation and the escape routes, help to assess the seriousness of the situation and provide the basis for the most appropriate decision making. UAS sensors operating in semiautomatic mode are capable of effectively measuring larger areas, while the ground personnel can be at a safe distance, and far, hard-to-reach locations, can be explored. UAS can also serve as a complement to periodic preventive dosimetry measurements around nuclear power plants. The currently used dosimetry monitoring stations are static, so they cannot dynamically respond to fast measurement requests in different locations. Illustrative is the example of the Sellafield Nuclear Power Plant in the UK, where the static monitoring station reported radiation leakage, which ultimately led to NPP shutdown. Subsequently, investigation revealed that the increased levels of the measured quantities had been caused by a natural radioactive source, located outside the nuclear power plant area, raised by the wind. In such a situation, a mobile detection unit located on an unmanned device would have effectively identify the source of the radiation [2].

\section{RADIATION MONITORING SYSTEM}

The main purpose of the Radiation Monitoring System (RMS) in combination with an Unmanned Aerial Vehicle (UAV) is the creation of UAS. Rapid deployment of the UAS in case of radiation event, which is its key feature, shall reduce the radiation burden on workers and on public. The system can be applied in the vicinity of a nuclear power plant (NPP) or at any location, where source of ionizing radiation could be present. Individual modules of RMS have been designed to operate with UAV without influencing functionality of each component, to provide sufficient information for the dosimetry staff and to achieve high standard of reliability. The key features of the RMS are the modularity, the custom independent in-house control software, the possibility to hibernate and subsequently activate the system upon specific incentives, the easy-to-wipe anti-contamination layer of sensors and the compatibility with various UAV carriers. 
The originality of the RMS lies in optimized compatibility with UAVs and modularity enabling implementation of various radiation sensors. The proposed solution involves the parallel operation of several UAVs, their efficient cooperation with the ground station and the deployment of modular sensor nodes, which can be linked to a chain. The proposed management of multiple nodes ensures greater flexibility for fast deployment and more efficient mapping of large territories, compared to a single node system. A system of measuring nodes, optimized for minimal power consumption, distributed by the UAVs in the area of interest, can provide information on the local radiation situation for even several weeks. The deployment of this system is foreseen in situations and at locations where the risk of radiation exposure on personal responsible for radiation measurements is expected. The modularity of this system also makes possible to be used in the R\&D field. The biggest advantage of the system is the low weight of the modules and extreme operation time, which in case of energy saving mode can achieve one month.

\section{DETAILED DESCRIPTION OF THE RMS MODULES}

The RMS is a modular system and is still in development. The current version consists of the RMS-000 communication and control module, the RMS-WASP communication software and three sensor modules (RMS-001, RMS-002, RMS-003). RMS-001 is the radiation measurement module, RMS-002 the air sampler module and RMS-003 the GPS tracker. The schematic view of the system is shown in Fig. 1.

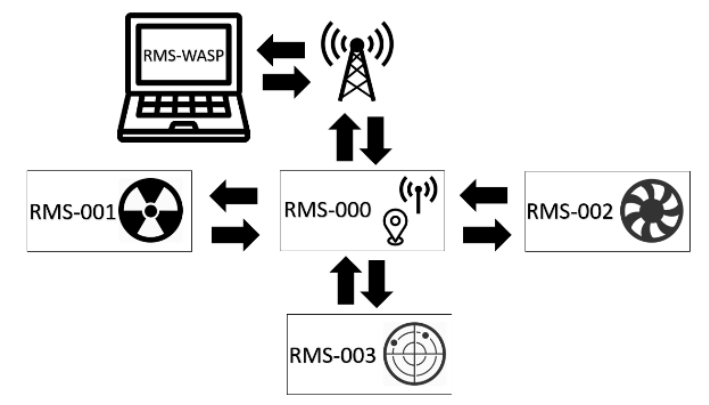

Fig. 1. 1. The schematic view of RMS modules.

\section{A. RMS-000 Communication and control module}

One of the essential parts of the RMS is the RMS-000 communication and control module. It serves to support the operation of the measurement modules and acts as a gateway between the ground station and the sensors. It makes efficient use of the programmable microcontroller and uses it as its brain. Considering that in a case of nuclear accident or other radiological threat the mobile networks might not be available, the emphasis in the design of the RMS-000 module was placed on securing independent communication and electricity supply channels. To achieve the maximum communication range and good penetration, $866 \mathrm{MHz}$ ISM band and sequential communication mode were selected. The communication antenna, connected via the USB port of the computer, is used to receive the signal from the RMS-000 node. Both modules provide 2-way encrypted communication. The signal transmission is routed in regular time intervals, defined by the user. The RMS- 000 module also provides device positioning with GPS co-ordinates and is transmitted to the ground station within a single message that includes also the measured parameters from the RMS-001 or RMS-002 modules. The main parameters of the RMS-000 module are listed in Table I.
TABLE I. MAIN PARAMETERS OF THE RMS-000 MODULE [3]

\begin{tabular}{|l|l|}
\hline \multicolumn{1}{|c|}{ Application } & \multicolumn{1}{c|}{ Modularization } \\
\hline Communication & $\begin{array}{l}\text { Primary }- \text { Radio in } 866 \mathrm{MHz} \text { EU ISM } \\
\text { band }\end{array}$ \\
\hline Range & Up to 20 km for 1 node \\
\hline Positioning & External GPS, precision $<1 \mathrm{~m}$ \\
\hline Connectivity & RMS-001, RMS-002, RMS-003 \\
\hline Supply & Independent Li-Po batteries \\
\hline
\end{tabular}

\section{B. RMS-001 Radiation sensor module}

The RMS-001 radiation sensor module serves for the online measurement of effective dose rate of gamma and beta radiation. The major parts of the module are the radiation sensor board and the J305 $\beta$ GM detector. The sensor board, the RMS-000 and the battery are placed in a protective casing made of carbon fiber material. The casing is equipped by the connectors necessary for the communication of the RMS-000 module with ground station. The GM tube and the carbon fiber casing are placed in the outer casing, which provides IP56 protection against dust and humidity. The current configuration allows measurement of an effective dose rate of gamma and partly beta radiation, ranging from the natural background level to $277 \mu \mathrm{Sv} / \mathrm{h}$ (up to $100 \mu \mathrm{Sv} / \mathrm{h}$ without significant impact of dead-time). The operative replacement of the GM tube is possible for another unit meeting the dimensional and supply conditions of the design. The main parameters of the RMS-001 module are presented in Table II.

TABLE II. MAIN PARAMETERS OF THE RMS-001 MODULE [3]

\begin{tabular}{|l|l|}
\hline \multicolumn{1}{|c|}{ Application } & \multicolumn{1}{c|}{ Measurement of effective dose rate } \\
\hline Detector type & GM tubes \\
\hline Type of radiation & gamma, beta \\
\hline Active measurement & $>48 \mathrm{~h}$ (continuous with GPS) \\
\hline Static measurement & $>1$ week (continuous without GPS) \\
\hline Control measurement & $>4$ weeks $($, stand-by“ and regular) \\
\hline Measurement range & $50 \mathrm{nSv} / \mathrm{h}-277 \mu \mathrm{Sv} / \mathrm{h}$ \\
\hline Measurement range & $200 \mathrm{nSv} / \mathrm{h}-10 \mathrm{~Sv} / \mathrm{h}$ \\
\hline Weight of the node & $0.5 \mathrm{~kg}$ \\
\hline
\end{tabular}

\section{RMS-002 Air sampler module}

The RMS-002 air sampler module serves to demonstrate the air sampling capability through a removable aerosol filter which intended use is to capture radioactive particles carried by aerosols in case of a nuclear accident. The filters can be subsequently used for spectral analysis to identify key radioisotopes. The module consists of a sensor board, removable filter, special LiPo battery, blower and flowmeter. The electronic parts (sensors and RMS-000) and the suction nozzle are located in a box made of carbon material. Currently the device is able to perform air sampling at speed that corresponds and surpasses to human respiration rate. The main parameters of the RMS-002 module are listed in Table III. 
TABLE III. MAIN PARAMETERS OF THE RMS-002 MODULE [3]

\begin{tabular}{ll}
\hline \multicolumn{1}{c}{ Application } & Aerosol collection for spectral analysis \\
\hline $\begin{array}{l}\text { Replaceable filter } \\
\text { Operation time }\end{array}$ & $\begin{array}{l}\text { Standard diam. } 5 \mathrm{~cm} \\
90-120 \mathrm{~min} .\end{array}$ \\
Air flow range & $0-301 / \mathrm{min} .$, upgradable to $55 \mathrm{l} / \mathrm{min}$. \\
Measurement & Actual air flow, total air volume. \\
Operation & $\begin{array}{l}\text { Continuous or sequential (remote control) } \\
\text { Upgradable to GPS position. }\end{array}$ \\
Casing & $\begin{array}{l}\text { Carbon fiber casing } \\
\text { External GM module, spectral analysis } \\
\text { module } \\
\text { Weight of the node }\end{array}$ \\
\hline
\end{tabular}

\section{RSM-WASP Control software}

The RMS-WASP control software has been developed to ensure the communication between nodes and to provide the user with a simple user-friendly environment, which however summarizes all the required parameters right on the screen, see Fig. 2. The software was developed in the ECLIPSE environment in $\mathrm{C}++$ language using wxWidgets multiplatform libraries to create the GUI (graphical user interface) of the program. The communication between the measuring nodes is secured by configuring the receiving module, which requires a serial port configuration using the RMS-WASP software. The control message is encrypted using the "CRC MODBUS-16" cipher. The measurement data is treated in real time, and the results can be visualized in a form of radiation maps. The results are processed to the specific " $k m l$ " file that can be directly visualized using QGIS - Open Street Map, Google Earth or other mapping software. This functionality involves the creation of a contoured radiation map directly plotted into real geographic coordinates, indicating also the trajectory of the unmanned device flight. In the current version of the software, the radiation data is transformed to effective doses rate based on the count rare and the calibration constant of the used GM tube. The program interface also enables switching the signal processing on/off, which is an important feature in case of fast transport of the UAV between the measuring points.

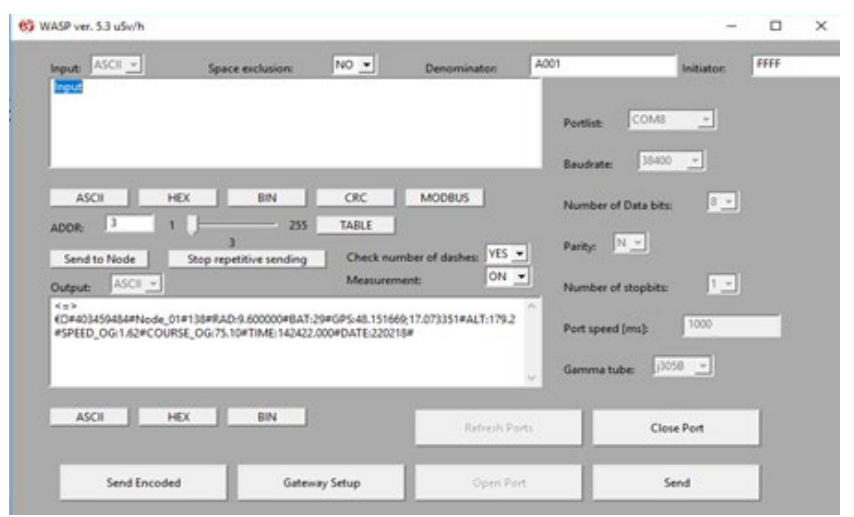

Fig. 2. RMS-WASP control software

\section{E. Currently used UAV system}

Although the RMS is compatible with almost every UAV that meets the required payload capacity, our reference UAV type is the DJI MATRICE - 600, owned and operated by UAVONIC ltd. This UAV was used in case of all testing and demonstration activities performed so far. The main parameters can be found in [4] and the UAV can be seen in Fig. 3.

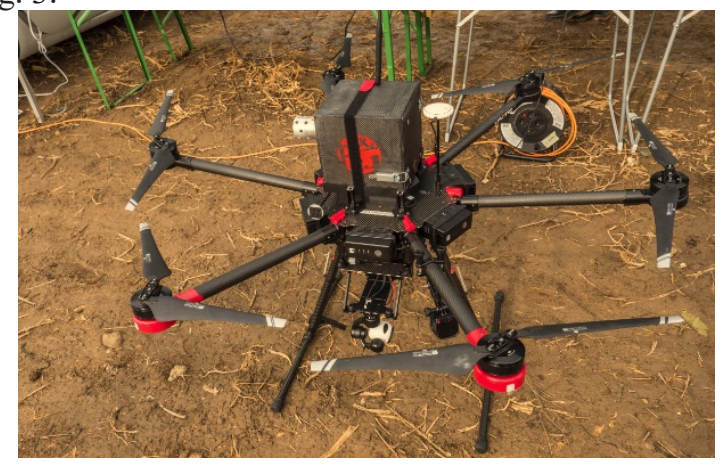

Fig. 3. DJI matrice 600 with the RMS modules.

\section{LABORATORY TESTING AND CALIBRATION}

In the development phase, the sensor modules and the RMS-WASP control software were intensively tested. First, to verify the functionality of components, the nodes were tested individually. To verify the gamma conversion factor of the J305 $\beta$ GM tube the Thermo-Fisher FH 40G-L10 [5] handheld multi-purpose digital survey meter was used. It is a wide range digital Geiger counter suitable for nearly all measurement tasks arising in radiation protection. It is a gas filled detector that measures $\mathrm{H}^{*}(10)$ ambient dose equivalent. In order to provide stabilized results, the detector uses time integration constants that are functions of the measured dose rate.

For the experiments three sources of gamma radiation were used, Co-57, Cs-137 and Co-60. The last two sources are commonly used calibration sources. Co-57 was used, in order to evaluate the effectiveness of the sensor module to measure complicated gamma decay. The experimental setup (see Fig. 5) consists of a sliding bench, an adjustable holder, a lead shielding and of the detection position. The gamma sources were placed at exactly the same height in every case and 6 distances from the detector were investigated, $10-60 \mathrm{~cm}$. The results from the FH 40G-L10 certified detector were read directly from the display and evaluated at regular time intervals. The results from the RMS-001 module were directly stored in text file on the measurement laptop. The results from the text file were averaged and normalized so as the results from both detectors were in the same time range. For the purpose of the results verification obtained by measurement and from the future development, the experimental setup was modeled in SCALE6 system and all measurements were simulated.

The obtained results showed that the precision of the RMS-001 radiation measurement module is comparable with the certified detector, however the death time of the detection tube plays important role. For real application, when the level of radiation exceeds $100 \mu \mathrm{Sv} / \mathrm{h}$ a GM tube designed for higher dose rate will have to be used. It was found out, that the first configuration was also sensitive to beta particles and X-ray. If the goal is to measure pure gamma radiation the detector must be shielded against beta particles and X-rays by material that has minimal cross section for the interaction with the abovementioned types of radiation. 


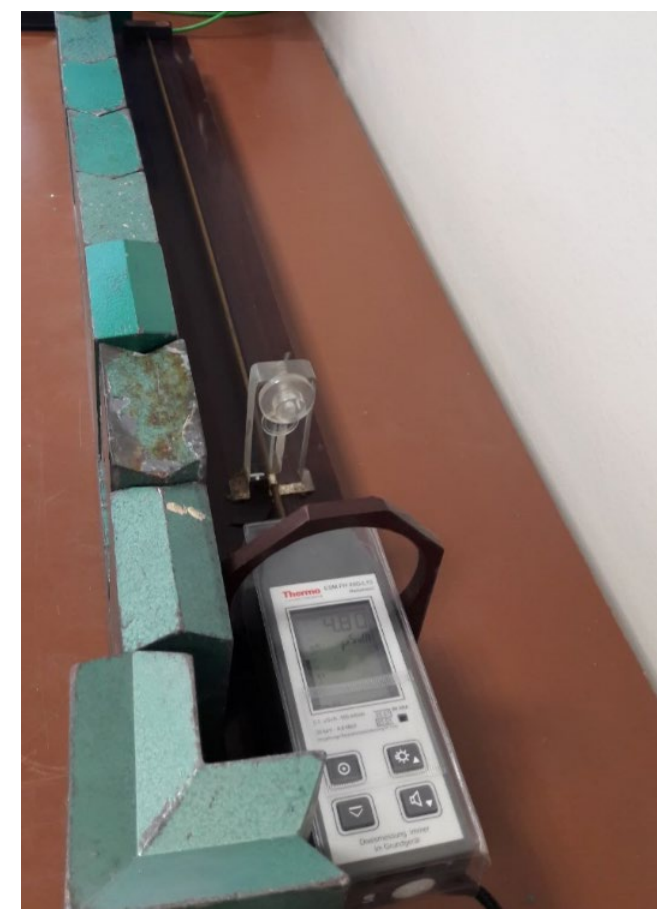

Fig. 4. The experimental workspace

\section{DEMONSTRATION OF RMS AND UAV SYSTEM}

Demonstration of the use of the developed technology was carried out as part of the regular emergency planning and preparedness of EBO NPP on 26th October 2017. The demo flight was carried out by the staff and technology of UAVONIC ltd as a proposed scenario. The exercises were attended by the staff of the radiation protection, physical protection and dosimetry of SE a.s. and also the Director of EBO V2 NPP. The radiation map created from the measurements during the exercise is shown in Fig. 4. The specification of the locality, where the demonstration was carried out, is that in near area the dosimetry stations of Slovak Hydrometeorological Institute (SHMI) and NPP Jaslovské Bohunice are placed. Mean value of the dose rate measured during demonstration is compared to the values of SHMI and NPP JB from periodical monitoring of the locality in Table IV.

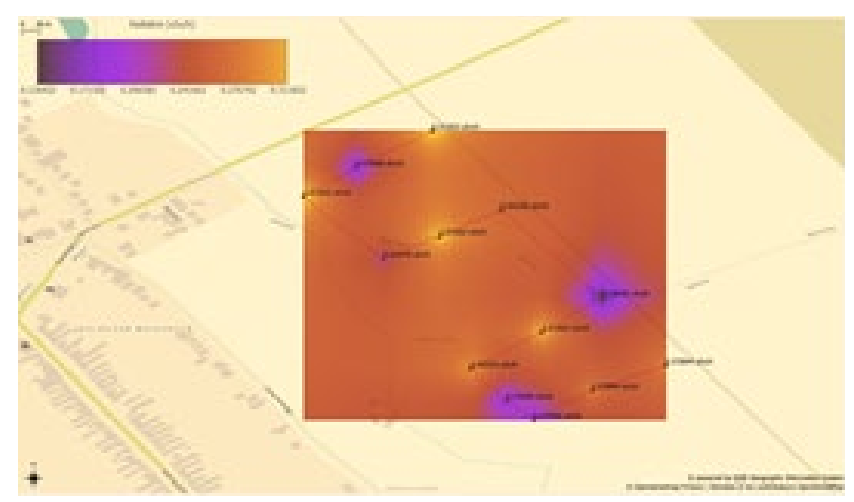

Fig. 5. Radiation map from the demonstration flight.

TABLE IV. DOSE RATE MEASUREMENTS (nSv/h)

\begin{tabular}{ccc}
\hline RMS-001 & SHMI [6] & NPP JB [6] \\
\hline $247.36 \pm 61.34$ & $124.19 \pm 7.41$ & $82.25 \pm 2.94$ \\
\hline
\end{tabular}

Differences between individual data are caused by different measurement technique and measurement conditions. Especially in our case the main factor is the short integration constant (25 seconds), the low number of measured intervals (13) and the calibration constant of the GM tube $(123,15 \mathrm{cpm} / \mu \mathrm{Sv} / \mathrm{h})$ where the statistical character of the background radiation plays an important role. Though the operational range of the J305 $\beta \mathrm{GM}$ tube starts from $50 \mathrm{nSv} / \mathrm{h}$, this GM tube was not designed for precise background measurement. In case of the average $247.36 \mathrm{nSv} / \mathrm{h}$ the GM tube accounted for only 0.45 counts per second, thus increase of measured counts by $1 \mathrm{cpm}$ may cause significant deviation in the results. However, if precise background measurements are to be carried out, the J305 $\beta$ GM tube can be simply replaced, without requiring the RMS electronic and software parts to be modified. Data of SHMI and NPP JB are the mean value of monthly measurement with integration constant 10 min and 24 hours respectively.

\section{CONCLUSION}

Although the design of the current generation of NPPs incorporates features that minimize the risk of large radioactive releases outside the reactor, it is still important to focus on the development of systems that can mitigate the consequences of such events. In situations when the level of radiation does not permit the personal to perform the required measurements, online unmanned radiation monitoring systems may come to the play. Such a system has been developed in the cooperation of the B\&J NUCLEAR ltd. and UAVONIC ltd. companies. It is the RMS-00x technology and its main features are the modularity, long operation time, high level of reliability and the operation with an UAV system. Currently the system consists of the RMS- 000 communication module, 3 measuring modules RMS-001, RMS-002 and RMS-003 and the control software RMS-WASP. This configuration makes possible to measure the effective dose of gamma and beta radiation up to the level of $277 \mu \mathrm{Sv} / \mathrm{h}$, air sampling with the speed twice to the human respiration rate, collection of the parameters of the measurement environment and the creation of online radiation maps. The RMS-001 module was tested and calibrated using various radioactive sources and certified measurement instruments at INPE FEI STU, later the testing was performed in environmental conditions. The obtained results showed that the precision of the RMS-001 radiation measurement module is comparable with the certified detector, however the death time of the detection tube plays important role. Similarly, the RMS-002 module was first calibrated in laboratory conditions. Later the data transfer capabilities were evaluated in real environmental conditions. Currently the radiation measuring module is being upgraded to perform the measurement of effective doses rate up to the level of $2 \mathrm{~Sv} / \mathrm{h}$. Also modules for neutron dose rate measurements and online gamma spectrometry are being developed. We believe that our system could contribute to enhance the level radiation safety of nuclear power plants in Slovakia and also abroad.

\section{ACKNOWLEDGMENT}

This work was supported by the B\&J NUCLEAR ltd., the UAVNOC ltd. and; the Slovak Research and Development Agency [APVV-16-0288]. 


\section{REFERENCES}

[1] A.J. Gonzáles, et al. "Radiological protection issues arising during and after the Fukushima nuclear reactor accident", J. Radiol. Prot., 33, 497571 (2015).

[2] C. Beylone, Leveraging Drones to Improve Nuclear Facility Security and Safety, online:

https://www.chathamhouse.org/expert/comment/16722, (2017)

[3] $\breve{S}$. Čerba, Callibration of the radiation monitoring module Martan (in Slovak), In B\&J NUCLEAR ltd. internal report, 2017, undisclosed
[4] DJI, MATRICE 600 user manual, online: https://dl.djicdn.com/downloads/m600/20171017/Matrice_600_User_ Manual_v1.0_EN.pdf, (2017)

[5] ThermoFisher Scientific, „FH 40 G Multi-Purpose Digital Survey Meter - product catalogue“, 2017, online: https://www.thermofisher.com/order/catalog/product/4254002

[6] T. Melicherová, et al. Záverečná ročná správa Čiastkového monitorovacieho systému "Rádioaktivita životného prostredia" 2017, in SHMI and MŽP report, 2017, online:

http://www.shmu.sk/File/radioaktivita/Zaverecna_sprava_CMS_Radi oaktivita_2017_final.pdf 